IZA DP No. 6954

Is There a Southern-Sclerosis? Worker Reallocation and Regional Unemployment in Italy

Chiara Mussida

Francesco Pastore

October 2012 


\title{
Is There a Southern-Sclerosis? Worker Reallocation and Regional Unemployment in Italy
}

\author{
Chiara Mussida \\ Università Cattolica del Sacro Cuore \\ Francesco Pastore \\ Seconda Università di Napoli \\ and IZA
}
Discussion Paper No. 6954
October 2012

\author{
IZA \\ P.O. Box 7240 \\ 53072 Bonn \\ Germany \\ Phone: +49-228-3894-0 \\ Fax: +49-228-3894-180 \\ E-mail: iza@iza.org
}

\begin{abstract}
Any opinions expressed here are those of the author(s) and not those of IZA. Research published in this series may include views on policy, but the institute itself takes no institutional policy positions. The IZA research network is committed to the IZA Guiding Principles of Research Integrity.

The Institute for the Study of Labor (IZA) in Bonn is a local and virtual international research center and a place of communication between science, politics and business. IZA is an independent nonprofit organization supported by Deutsche Post Foundation. The center is associated with the University of Bonn and offers a stimulating research environment through its international network, workshops and conferences, data service, project support, research visits and doctoral program. IZA engages in (i) original and internationally competitive research in all fields of labor economics, (ii) development of policy concepts, and (iii) dissemination of research results and concepts to the interested public.
\end{abstract}

IZA Discussion Papers often represent preliminary work and are circulated to encourage discussion. Citation of such a paper should account for its provisional character. A revised version may be available directly from the author. 


\section{ABSTRACT \\ Is There a Southern-Sclerosis? Worker Reallocation and Regional Unemployment in Italy*}

Theoretical reasoning justifies different signs of the relationship between the local variation in unemployment rates and the extent of workers reallocation. This paper aims to test different theoretical hypotheses in the case of Italy by using the longitudinal files of the Italian labour force survey over the years from 2004 to 2010. We find that labour turnover, as well as inflows and outflows separately, differ significantly at the regional level and are ceteris paribus positively related to the unemployment rate. In addition, we study the determinants of labour turnover across NUTS1 and NUTS2 geographical units and find that it correlates positively with structural change, as measured by the Lilien index, and negatively with the degree of industrial concentration, as measured by the Herfindahl index. Once we control for sectoral shifts and industrial concentration, we note a reduction of between 25 and $40 \%$ of the regional gap in labour turnover rates. This general conclusion is robust to the use of different control variables.

JEL Classification: $\quad$ C33, J63, P25, P52, R23

Keywords: regional unemployment, labour turnover, labour reallocation, structural change

Corresponding author:

Francesco Pastore

Department of Law

Seconda Università di Napoli

Via Mazzocchi 5

81055 Santa Maria Capua Vetere (Caserta)

Italy

E-mail: francesco.pastore@unina2.it

\footnotetext{
* A previous version of this paper has been presented at the XXVII AIEL Conference, September 2012. We thank all seminar participants for useful comments. We wish also to thank Carlo Lucarelli for providing us with the longitudinal structure of the Italian labour force survey. Any remaining error is our responsibility only.
} 


\section{Introduction}

Based on theoretical reasoning, the relationship between worker reallocation and the unemployment rate can be of different nature. There could be a positive relationship, like in Aghion and Blanchard (1994), a negative one, like in Krugman (1994), or no relationship. Intuitively, in the latter two cases, high unemployment regions have an insufficient ability to create new jobs. In the former case, large turnover is the result of continuous high rates of layoff and hiring, thus leading to a (possibly temporary) unemployment increase.

In turn, industrial restructuring causing sectoral shifts might explain the high level of turnover of high unemployment regions (so-called Lilien hypothesis). Alternatively, large labour market flows might be the sign of greater labour market flexibility, which is, however, usually associated with efficient labour markets and thus relatively lower unemployment (so-called Krugman hypothesis).

In this paper we empirically discriminate between these alternative theoretical hypotheses by exploiting the geographical differentiation of labour turnover (and also worker reallocation) and unemployment rates.

Ferragina and Pastore (2008) suggest that this test constitutes a "screening device" to distinguish the case when unemployment is due also to some region-specific shock (namely the high degree of labour turnover in high unemployment regions caused by industrial restructuring) and when it is instead due solely to labour market rigidities. Note that the policy implications of these alternative hypotheses are partly different, since a low job finding rate in high unemployment regions essentially suggests the need for supply side policies, whilst a positive relationship between labour market turnover and unemployment requires interventions on the demand side as well.

The empirical evidence available in the literature is neither large nor unambiguous. The main reason is the limited availability of suitable longitudinal data to measure labour market dynamics at the local level. A number of papers find a positive relationship between labour turnover and the regional unemployment rate (for the UK: Armstrong and Taylor (1985); for Poland: Newell and Pastore (2006); Pastore and Tyrowicz (2010); for Italy: Contini and Trivellato (2005); Naticchioni et al. (2006); Basile et al. (2012)); others find no relationship (for a bench of Eastern European countries: Boeri and Scarpetta (1996); Boeri (2000); 2001WorldBank (2001); Rutkowski (2003); for the UK: Robson (2001)).

In addition, the sign of the relationship under scrutiny might change over time, which has never been accounted for earlier. Except for Pastore and Tyrowicz (2010) and Basile et al. (2012), who include a panel dimension, previous research was mainly based on analysis of short periods of time.

In this paper, we try to fill some of the gaps of the existing literature, by using longitudinal data on Italy over the period 2004-2010. To our knowledge, this is the first paper to study in a systematic way the geographical relationship between labour turnover and the rate of unemployment using labour force survey (LFS) data. Until recently, indeed, statistical information on workers reallocation based on labour force survey data was not available. 
The purpose of our analysis is twofold. First, we aim at understanding the nature of the relationship/link between local worker reallocation, - turnover and its main components (inflows and outflows) - and unemployment. Second, based on the nature of the relationship, we aim at understanding the sources of worker reallocation and how it differs across regions. We use the micro-dimension of the data to study the determinants of labour reallocation at the individual level. This allows us controlling for factors that might be important correlates of workers' reallocation and unemployment rates at a local level.

The case of Italy is particularly interesting not only because of its famous and persistent regional unemployment differences, but also because it allows comparing the better developed more dynamical regions of the North and the static regions of the South.

One explanation of the geographical differentiation of worker reallocation (WR) and worker turnover (WT) hinges on the differences in the local labour market structure (e.g. OECD, 2004). We study their correlation across geographical units not only with the level of industrial turbulence, but also with that of unemployment.

We find evidence of a positive relationship between WT (and WR), on the one hand, and the unemployment rate across regions, on the other hand. Quite surprisingly for those who consider WT as a proxy for labour market flexibility, in all the considered years, indeed, the rate of turnover is higher in those regions where also the unemployment rate is higher.

We also consider the WT rate and its main components of accession and separations rates. As expected we find evidence of regional discrepancies between such indicators. The high-unemployment South is the geographical area with the highest WT especially with respect to the North-West.

To examine the possible sources of worker reallocation and the factors behind its regional discrepancies, we carry out econometric estimates of the cross-regional determinants of the WT rate in pooled estimates. In a first attempt, we add control variables for such individual characteristics as age, gender and education, type of occupation, sector of activity (public versus private), firm size, type of contract (permanent versus temporary). The estimates suggest that all the considered explanatory variables play a role in explaining the labour turnover and its regional differences. We find that, similar to what previously found in Newell and Pastore (2006) with reference to Poland, the youngest age segment shows a highest probability of reallocation as compared to the other age groups, with the partial exception of the eldest workers. This latter, indeed, more frequently move to inactivity.

The worker turnover reduces with education and, as expected also based on previous studies (e.g. Naticchioni et al., 2006), with firm size and into the public sector. Worker reallocation increases for temporary workers. This is in line with expectations.

In our estimates we also include indicators of sectoral shifts and industrial concentration, as possible sources of worker turnover and of its regional differences. We find that those indicators are quite relevant determinants of worker turnover and of its geographical discrepancies. As to the effect of structural change and economic diversification, we find that WT correlates positively with structural change, as measured by the Lilien index, and 
negatively with the degree of industrial concentration, as measured by the Herfindahl index. Once we control for these two factors, we note a reduction of between $25 \%$ and $40 \%$ of the regional gap in terms of worker turnover.

The paper proceeds as follows. Section 2 offers a survey of the literature and the relevant theoretical foundations as well as some available empirical evidence. Section 3 sketches the methodology and describes the data. Sections 4 offers our findings for the descriptive and econometric analyses. Section 5 concludes.

\section{A survey of the literature}

Before presenting the data and the econometric methodology, this section defines the main hypotheses to test.

The first section focuses on the link between local worker reallocation and unemployment: it shows that different a priori relationships might possibly exist among these two variables and brings to the fore three alternative hypotheses to test. The section also summarizes the main empirical contributions that support each hypothesis and it discusses the main findings of the literature on Italy.

The ensuing section argues that the empirical literature has attempted to disentangle three possible sources of differences in worker reallocation across regions, namely sectoral shifts, aggregate disturbances and job-to-job moves.

\subsection{The link between local worker reallocation and unemployment}

The Aghion and Blanchard (1994) model can be used as a theoretical framework to think of the way how labour market dynamics affects the regional distribution of unemployment.

Assume that the hiring rate is a bell-shaped function of unemployment. This nonlinearity depends on the double effect of unemployment on hiring: on the one hand, unemployment reduces wages, and therefore fosters private sector growth, since with unemployment increasing there is greater competition for jobs and downward pressure on wages; on the other hand, though, unemployment raises the level of taxes per worker, to pay unemployment benefits, thus reducing profits. Assume also that the separation rate is a control variable and it is therefore independent of unemployment. When the separation rate is above (below) the hiring rate, unemployment increases (reduces).

As Ferragina and Pastore (2008) argue, although used to explain national unemployment, this framework might also apply to local labour market differences, provided that regions are separated from each other due to low migration / commuting. Then, three alternative hypotheses are in order:

$H_{0}$ : worker reallocation is independent of regional unemployment;

$H_{1}$ : worker reallocation correlates positively with regional unemployment; 
$H_{2}$ : worker reallocation correlates negatively with regional unemployment.

According to $H_{0}$, the same aggregate shock yields asymmetric effects across regions. High unemployment regions are such because they have experienced dramatic structural change ${ }^{1}$ sometime in the past, with a too high separation rate at the beginning, so that the unemployment rate exceeds its equilibrium level. Only at a later stage separation rates converge across regions.

According to $H_{1}$, in high unemployment regions more jobs are destroyed and created at the same time. In the spirit of the Aghion and Blanchard (1994) model, this happens because each region has a specific rate of structural change, but other hypotheses are also possible, as later discussion will show.

The well-known Krugman (1994) hypothesis provides an explanation for $H_{2}$. It states that the higher is the degree of worker reallocation experienced in a country (region), the lower is also the unemployment rate: greater worker reallocation would mean, in fact, a higher degree of labour market flexibility and therefore lower frictional and long-term unemployment. In other words, there would be a spatially asymmetric impact of rigid labour market institutions.

In fact, the above hypotheses allow setting up an empirical law to detect the case when unemployment is due to some region-specific shock $\left(H_{1}\right)$ and when it is due to labour market rigidities $\left(\mathrm{H}_{2}\right.$ or $\left.\mathrm{H}_{0}\right)$. The policy implications of these alternative hypotheses are partly different.

Whilst a low job finding rate essentially suggests the need for supply side policies in favour of the long-term unemployed, namely increasing labour market flexibility and/or educational reforms and active labour market policy on a large scale, $H_{1}$ also requires interventions on the demand side. For instance, assuming that the government is able to do so, it should reduce the rate of separation and/or increase the life expectancy of private businesses in the high unemployment regions. This might in turn require removing the sources of structural change in high unemployment regions whatever they are.

The empirical evidence available in the literature is neither large nor unambiguous. The main reason is the limited availability of suitable longitudinal data to measure labour market dynamics at a local level. In addition, the sign of the relation under consideration might change according to the data used and over time.

Robson (2001) finds no correlation between worker reallocation and unemployment across the UK macro-regions in the decade 1984-1994. In the case of transition countries, some authors (such as Boeri and Scarpetta (1996); Boeri (2000); WorldBank (2001); Rutkowski (2003) interpret the low rate of monthly labour turnover computed as based on employment registry data of high unemployment regions as a consequence of low labour

\footnotetext{
${ }^{1}$ Note that here structural change is meant as a process of industrial change which does not need to go necessarily in the direction of increasing the productive and technological level of the region. In other words, a higher degree of structural change does not need necessarily to be associated to a high rate of economic development. It may be a consequence of greater industrial turbulence.
} 
market dynamism.

Extensive related literature highlights, among other things, the role of rigid wages and legislation protecting employment, non-employment subsidies and early retirement schemes (see, among others, Boeri (2000); WorldBank (2001); Funck and Pizzati (2002, 2003)). Garonna and Sica (2000) find a negative association between the Lilien index of structural change and the unemployment rate in Italy: in particular, sectoral and interregional reallocations in Italy would reduce unemployment, rather than increasing it. Bockerman (2003) takes the same result for Finland as evidence of Schumpeterian "creative destruction".

Other studies find evidence that high unemployment regions are those where the degree of worker turnover is higher.

For the UK, Armstrong and Taylor (1985) use the male monthly inflow from the employment registry data and find that they positively correlate to local unemployment rates.

For Poland, Newell and Pastore (2006) use labour force survey measures of annual gross worker flows and find a correlation coefficient between the job separation rate and the unemployment rate of 0.76, significant at the one-percent level, during the period 1994-1997. Pastore and Tyrowicz (2010) confirm previous findings regarding Poland using registry level data relative to the years from 2000 to 2008 .

For Italy, Contini and Trivellato (2005) find the highest turnover rate in the traditionally high unemployment regions of Mezzogiorno. Naticchioni et al. (2006) find similar evidence using the ISFOL panel based on ISTAT Labour Force Survey data. Using Local Labour Systems (LLSs) data, Basile et al. (2012) also report a strong correlation between worker reallocation and unemployment across LLSs. Sectoral shifts and the degree of specialization exert a negative role on unemployment dynamics.

A related issue is whether it is the inflow or the outflow rate to affect unemployment over time. Blanchard and Summers (1986) claim that a higher degree of cyclicality of the hiring rate is behind the fluctuations of the US aggregate unemployment. Burda and Wyplosz (1994) note that European countries differ in terms of the degree of cyclicality of hiring and firing rates. While some EU countries follow US trends, others, instead, have a cyclical firing rate. Layard et al. (1991) summarize this research partly confirming the hypothesis that a low job finding rate is behind high unemployment rates, due to the increase of the long-term unemployment and its persistent impact on average unemployment.

Revisiting this issue, Shimer (2007) has recently proposed a new methodology which points to the fact that the evolution of the job finding rate - and not that of the flow into unemployment - would reproduces the cyclicality observed in the unemployment rate. Hall (2005) subscribes to Shimer's view, whilst Petrongolo and Pissarides (2008), for the UK, France and Spain; Bachman and Peggy (2009) for Germany; Elsby et al. (2009) and Fujita and Ramey (2009) suggest alternative explanations.

Fujita and Ramey (2009) find that cyclical changes in the separation rate is negatively correlated with changes in productivity and move contemporaneously with them, whereas the job finding rate is positively correlated with and tends to lag after productivity, which 
is consistent with the Aghion and Blanchard (1994) theoretical framework adopted in this paper.

\subsection{The sources of (differences in) worker reallocation}

If $H_{1}$ holds true, what are the sources of the reallocation and why are they different across regions? Several hypotheses have been raised in the literature:

$H_{13}$ : different sectoral shifts across regions (Lilien hypothesis);

$H_{12}$ : aggregate disturbances with spatially asymmetric effects (Abraham and Katz hypotheses);

$H_{11}$ : a crowding out of employed job seekers in low unemployment regions (Burgess hypothesis).

According to $H_{13}$, some sectors/regions experience a permanent reduction in labour demand that causes local unemployment. Lilien (1982) found a positive correlation over time between the aggregate unemployment rate and the cross-industry dispersion of the employment growth rates in the US.

However, Abraham and Katz (1996) and a number of related studies (such as Neelin (1987); Fortin and Araar (19977)) argue against the underlying assumption that sectoral shifts can take place independent of aggregate labour demand reductions. ${ }^{2}$

For measuring the structural change in the demand for employment, Lilien developed an index that measures the standard deviation of the sectoral growth rate of employment from period $t-1$ to period $t$. For each region (or geographical area) of the country, the Lilien index measures the structural change in the demand for variance in industry employment growth as follows:

$$
\text { Lilien }=\left[\sum_{i=1}^{n} \frac{x_{i r t}}{x_{r t}}\left(\Delta \log x_{i r t}-\Delta \log x_{r t}\right)^{2}\right]^{\frac{1}{2}}
$$

where $i$ is the industry and $r$ is the region (or area of residence), whilst $x_{i r t}$ is the sectoral employment and $x_{r t}$ is the total employment. The first term in brackets is therefore the sectoral share of employment, and the second term is the log-change of the sectoral and total employment, respectively. Most studies use some variation of the Lilien index. ${ }^{3}$

\footnotetext{
${ }^{2}$ There are sources of structural change that tend to be transitory and others that are permanent. The former include the opening up to international trade of new competitors and the introduction of new technologies causing some productions to go out of market. Structural and permanent "weaknesses" of high unemployment regions, which cause their low competitiveness and attractiveness to investment from abroad, include: a) Low human and social capital endowment; b) High (organised) crime rates; c) Reduction in migration as an adjustment mechanism; d) Economic dependence on more developed regions; e) Poverty traps. For a more detailed analysis, see Caroleo and Pastore (2010).

${ }^{3}$ Among the available studies, it is worth mentioning Samson (1985) for Canada; Berg (1994), Barbone et al. (1999), Newell and Pastore (2006) for Poland; Krajnyàk and Sommer (2004) for the Czech Republic;
} 
Hyclak (1996) reports a negative correlation of -0.72 between sectoral shifts and net job growth in a sample of 200 US metropolitan areas over the years 1976-1984. Holzer (1991) proposes the sales growth rates to disentangle shifts between and within local markets and find that the former have much greater impact than the latter.

To overcome the criticisms against the Lilien index and its variations, the research in the field has pursued the aim of finding empirical ways to disentangle sectoral shifts and aggregate disturbances. Among the others, Neumann and Topel (1973) elaborate a macroeconomic model where the equilibrium level of unemployment in a region depends on its exposure to the risk of within-industry employment shocks and on their degree of industrial diversity. Their approach has stimulated further research.

Following Neumann and Topel (1973), several authors (see, among others Simon, 1988; Simon and Nardinelli, 1992; Chiarini and Piselli, 2000; Basile et al., 2012) have tried to control for aggregate disturbances including in the estimates some index of industrial concentration, such as the Gini or the Herfindahl-Hirshman index (HHI).

In detail, the HHI measures the degree of industrial concentration. It is the squared sum of the employment shares, computed as follows:

$$
H H I=\sum_{i=1}^{n} \frac{x_{i r t}{ }^{2}}{x_{r t}}
$$

where $x_{i r t}$ is the market share of firm $i$ in the market, and $n$ is the number of firms. A higher HHI implies a less competitive industry and high concentration of employment into the industries/firms.

The rationale is that common shocks may generate asymmetric effects across industries: in fact, regions that are highly specialized in low-sensitive industries are expected to exhibit low vulnerability to aggregate disturbances; and vice versa.

More generally, two alternative hypotheses are in order as to the local impact of aggregate shocks: according to Jacobs (1969), aggregate shocks should hit more the least diversified regions because of what Simon (1988) called the portfolio effect in the labour market; vice versa, Glaeser et al. (1992) pointed to Marshallian effects to suggest that more specialised industries might provide higher externalities and growth which should absorb the negative effect of aggregate shocks. Marshall (1890) himself noted also that the negative employment effects of aggregate shocks on specialised areas may be reduced in large regions, in which several distinct industries are strongly developed (for surveys of the literature, see Elhorst, 2003; Ferragina and Pastore, 2008).

In the case of Italy, Basile et al. (2012) find evidence of the portfolio effect using data at a local labour market system level (travel to work areas).

Alternatively, Burgess (1993) assumes that the greater worker reallocation in high unemployment regions is due to the lower job opportunities for unemployed job seekers in low

Robson (2009) for the UK. 
unemployment regions. In these regions, in fact, the unemployed are crowded out by employed job seekers who are encouraged to search for better jobs. Consequently, one would observe a higher worker turnover in high unemployment regions simply because in these regions the unemployed who find jobs are a larger relative number with respect to their peers in low unemployment regions.

A number of studies have tested the Burgess hypothesis. Van Ours (1995) finds only partial evidence of competition between employed and unemployed job seekers in the Netherlands. Broersma (1997) finds similar evidence in the flexible UK and rigid Netherlands.

For the UK, Robson (2001) finds evidence of employed job seekers crowding out the unemployed especially in low unemployment regions. Burgess and Profit (1993) find that high unemployment levels in neighbouring areas raise the number of local vacancies but lower the local outflow from unemployment. Eriksson and Lagerström (2006) study the Swedish Applicant Database and find evidence that unemployed seekers face a lower contact probability than employed job seekers.

\section{Methodology and data}

\subsection{Aims of descriptive analysis}

The purpose of our descriptive analysis is to understand the nature of the link between local worker reallocation and unemployment. In other words, we test the alternative hypotheses presented in Section 2.1.

Note that in the theoretical literature worker reallocation is meant in a more general way as a reallocation of workers from a declining to an expanding sector, with or without intervening unemployment spells. From an empirical point of view we can then distinguish worker reallocation and worker turnover as follows.

The definitions adopted are based on Davis and Haltiwanger (1995) and the relevance of such indicators is examined by (among others) Blanchard and Diamond (1990), Davis et al. (1996), and, for Italy, by Contini (2002) and Naticchioni et al. (2006).

Worker reallocation $(W R)$ at time $t$ is the number of persons whose place of employment ${ }^{4}$ or employment status differs between $t-1$ and $t$. There are two definitions of $W R$. According to definition one, $W R$ is the number of job to job movements or changes in the place of employment (so called between-job moves definition). According to definition two, $W R$ includes also changes in the employment status (so called within-job moves definition). In detail, we include changes of the kind of occupation (from wage employment to self-employment and vice versa), contract type (from temporary to permanent and vice

\footnotetext{
${ }^{4}$ This is known as churning and it is one of the main cyclical indicators of the economy. For instance, a reduction of the churning is a signal of both a worsening of the current economic conditions and of worst future economic and occupational perspectives. For details, see Davis and Haltiwanger (1992) and the more recent work of Shimer (2007).
} 
versa), employment position according to a twelve-categories classification (ISTAT Classification of Professions 2001), and changes of the sector of economic activity (according to the ATECO classification with twelve classes/sectors). This definition allows therefore capturing all (or at least almost all) kinds of change into the employment status. By considering only job to job moves, definition one, instead, might lead to an underestimation of WR.

Both the definitions are considered in the descriptive analysis.

Worker turnover $(W T)$ at time $t$ is the number of accessions to employment from unemployment and inactivity plus the number of separations from employment to unemployment and inactivity, respectively. Therefore $W T$ does not include flows between unemployment and inactivity. $W R$ and $W T$ rates are computed by dividing WR and WT by the average employment level (between $t-1$ and $t$ ).

The comparison between the two indicators offers useful insights on labour mobility. If the difference between $W R$ and $W T$ is low, the additional mobility of workers changing employment status or place of employment is not very relevant. On the contrary, if the difference is high, the additional mobility of workers involved in $W R$ transitions is substantial. In our analysis, we calculate $W R$ (both between and within-job moves) and $W T$ at the geographical level (NUTS1 and NUTS2). ${ }^{5}$

\subsection{Aims of the econometric analysis}

The aim of the econometric analysis is to study the relationship between the regional (NUTS1 and NUTS2) unemployment rate and the rates of worker turnover and its main components, namely accession and separation rates. The aim is to test the hypotheses brought to the fore in the previous section.

After assessing the sign of the above relationship in terms of unconditional means, we test its robustness by means of multivariate analysis in a micro-econometric context using individual level data. We aim at understanding whether the relationship found among unconditional means holds also once controlling for a number of variables that could in principle affect the geographical distribution of worker turnover.

The factors behind the significant geographical discrepancies in worker turnover and reallocation might be different and independent of differences in the degree of structural change. In other words, the greater rate of worker turnover in some regions could be due to the concentration there of regional characteristics that are typically associated to greater worker turnover. We indeed consider several additional control variables (to the geographical area of residence) that might play a role in explaining why worker turnover differs significantly across regions.

We carry out a pooled logit estimate taking as a dependent variable the fact of having ex-

\footnotetext{
${ }^{5}$ This is the acronym of "Nomenclature of Units for Territorial Statistics". More precisely, we refer to the first level of disaggregation, NUTS1, corresponding to macro-regions, and to the second level, NUTS2, corresponding to regions.
} 
perienced a worker turnover flow in the last year, as defined in the previous section. Among the control variables we have individual characteristics (such as gender, age, educational level), the region of residence (three macro-areas of residence), and additional variables that proxy firm size, sector of employment (public/private) and type of contract (fixed term or permanent contract). In order to take into account possible time trends, we also control for the year over which flows are computed.

The regressors include factors able to affect the degree of worker turnover in a region. Take, for instance, the firm' size that is an indicator of market structure. Differences in the market structure, indeed, might explain differences in labour turnover at the local labour market level: the more competitive is the market structure in the local economy and therefore the greater is the share of small sized firms, the greater is also the degree of labour turnover. More in detail, the literature, such as OECD (1994), and for Italy Boeri (1996) and Naticchioni et al. (2006), shows that flow rates are inversely related to firm size. ${ }^{6}$

The latter contribution find that in Southern Italy the share of employment in small firms is higher than in the rest of Italy, especially compared to the North-West. The evidence suggests that the regional economic structure might affect the overall flow rate. In other words, the higher the share of employment in small firms, the higher will be the flow rates.

Differences in the age of individuals living in different regions might also affect the worker turnover gap. The higher is the proportion of young people living into a region the greater ceteris paribus its degree of turnover is expected to be. Low education and low skill workers tend also to experience a higher probability of labour turnover. A higher share of temporary and informal workers might also determine the turnover gap.

\subsection{Data}

Our sample is extracted from ISTAT Labour Force Survey data. This is a rotating panel survey based on the principles set out by the International Labour Organization (ILO) and on harmonized methodology across most of the countries in the OECD area. ${ }^{7}$ The longitudinal component of the survey comprises almost 70,000 individuals per year.

The sampling design of the survey is composed of two stages: municipalities are the stage one units, while households are the stage two units. Each household member is interviewed. The main difference between the two stages is that while for families a 2-2-2 rotation scheme is applied, the municipalities surveyed do not change over time. More specifically, a household was interviewed for two consecutive surveys and, after being excluded from the sample for two quarters, was interviewed for another two consecutive quarters. ${ }^{8}$

This rotation system makes it possible to maintain half the sample unchanged in two consecutive quarters and in quarters one year apart. In other words, the scheme implies a

\footnotetext{
${ }^{6}$ See also, for instance, Davis and Haltiwanger (1995), Boeri (1996).

${ }^{7}$ For a detailed description of the survey, see Gazzelloni (2006) and ISTAT (2009).

${ }^{8}$ For details on the sampling design, see Discenza and Lucarelli (2009).
} 
$50 \%$ overlapping of the theoretical sample to a quarter of the distance, a $25 \%$ overlapping to three quarters, a $50 \%$ to four quarters, and a $25 \%$ to five quarters.

We focus on annual flows over the years 2004-2010. In order to examine the worker reallocation and turnover of (almost) the overall labour force we include in our sample the employees over the age of 15 and under the age of 64 . We drop individuals over the age of 64 to avoid to get mixed up with retirement issues. We also drop the self-employed, the individuals who were in the army or with missing values for some important variables used in the econometric analysis.

Considering the working age individuals, 129,597 observations remain over the period examined.

\subsection{Variables}

Table 1 displays the descriptive statistics of the variables used in the econometric analysis of the worker turnover by area of residence and for Italy. The dependent variable, namely worker turnover, is a dummy variable for the presence/absence of worker turnover in the last year. ${ }^{9}$ The table clearly shows that WT is higher in the Centre-South, as it involves about $17 \%$ of the sample, while in the North it involves about $10 \%$ of the sample. This is clearly quite a large gap.

On average, 55.8\% of our sample of employees are men during the period 2004-2010. We distinguish between five age groups: very young workers (15-24 years old), young workers (25-34 years old), middle aged workers (35-44 years old) mature and older workers (45-54 an 55-64 years old, respectively). The Centre-South has on average a higher share of individuals in the youngest and oldest segment, whereas the share of the more stable prime-age group is lower in the Centre-South, probably also because of migration to the North.

Educational variables are defined according to UNESCO's International Standard Classification of Education (ISCED). The Italian LFS survey distinguishes between education completed in the lower secondary stage (ISCED 0-2), upper secondary education (ISCED 3 ), and post-secondary or tertiary education (ISCED 5-7). Almost half of the sample has a lower secondary educational attainment (48.2\%), 37.8\% attained an upper secondary education diploma and the remaining group (around 14\%) has a post-secondary or tertiary educational title. In the Centre-South there is a higher share of people holding a secondary school diploma and a university degree than in the North, due to the high share of public workers, who tend to hold a higher educational attainment level.

Indicators for the type of occupation (blue-collar or white-collar) ${ }^{10}$, the sector of economic activity (private or public sector), and the firm size (number of employees) are also

\footnotetext{
${ }^{9}$ The adopted definition of WT is given in Section 3.1.

${ }^{10}$ These occupational indicators are built on the basis of the International Standard Classification of Occupation (ISCO 88). Taking the three-digit ISCO categories, the white-collar indicator corresponds to categories 1 up to 4; the blue-collar indicator corresponds to categories 5 to 8 .
} 
Table 1: Summary Statistics by Area of Residence, 2004-2010

\begin{tabular}{|c|c|c|c|c|c|c|c|c|}
\hline & \multicolumn{2}{|c|}{ North-West } & \multicolumn{2}{|c|}{ North-East } & \multicolumn{2}{|c|}{ Centre-South } & \multicolumn{2}{|c|}{ Italy } \\
\hline & Mean & St. Dev & Mean & St. Dev & Mean & St. Dev & Mean & St. Dev \\
\hline Worker Turnover & .102 & .302 & .104 & .306 & .169 & .374 & .135 & .342 \\
\hline Male & .526 & .498 & .523 & .499 & .591 & .492 & .558 & .497 \\
\hline \multicolumn{9}{|l|}{ Age } \\
\hline$[15,24]$ & .092 & .288 & .098 & .297 & .093 & .289 & .093 & .291 \\
\hline$[25,34]$ & .239 & .427 & .241 & .428 & .221 & .415 & .231 & .421 \\
\hline$[35,44]$ & .326 & .469 & .327 & .469 & .295 & .456 & .311 & .463 \\
\hline$[45,54]$ & .269 & .444 & .327 & .440 & .275 & .447 & .271 & .444 \\
\hline$[55,64]$ & .073 & .261 & .071 & .258 & .116 & .321 & .094 & .292 \\
\hline \multicolumn{9}{|l|}{ Education $^{(\mathrm{a})}$} \\
\hline None, elementary, or lower secondary & .506 & .500 & .509 & .499 & .455 & .498 & .481 & .499 \\
\hline Upper secondary & .364 & .481 & .355 & .479 & .397 & .489 & .378 & .485 \\
\hline Post secondary or tertiary & .130 & .366 & .136 & .343 & .148 & .355 & .140 & .347 \\
\hline \multicolumn{9}{|l|}{ Firm size } \\
\hline$[1,15]$ & .344 & .475 & .346 & .476 & .366 & .482 & .355 & .479 \\
\hline$[16,49]$ & .229 & .421 & .246 & .431 & .232 & .422 & .235 & .434 \\
\hline$[50,250]$ & .229 & .419 & .288 & .419 & .197 & .398 & .213 & .409 \\
\hline$[250$, over $]$ & .139 & .346 & .118 & .323 & .110 & .313 & .119 & .325 \\
\hline Undefined & .166 & .235 & .187 & .240 & .095 & .293 & .215 & .411 \\
\hline Blue-collar & .400 & .490 & .397 & .489 & .438 & .496 & .418 & .493 \\
\hline White-collar & .597 & .490 & .603 & .489 & .562 & .496 & .582 & .493 \\
\hline Temporary contract & .059 & .279 & .061 & .302 & .128 & .334 & .077 & .267 \\
\hline Public Sector & .085 & .372 & .101 & .390 & .256 & .436 & .109 & .313 \\
\hline Herfindahl & .142 & .015 & .136 & .014 & .121 & .013 & .130 & .017 \\
\hline Lilien & .447 & .198 & .497 & .186 & .650 & .211 & .559 & .222 \\
\hline Observations & \multicolumn{2}{|c|}{35,885} & \multicolumn{2}{|c|}{29,834} & \multicolumn{2}{|c|}{63,878} & \multicolumn{2}{|c|}{129,597} \\
\hline
\end{tabular}

Note: Average values of mean and standard deviation for the period 2004-2010.

Source: Authors' elaborations on Italian Labour force survey data. 
included in the model, as they are likely to affect worker turnover. More than a half of our sample of employees is a white collar worker $(58.17 \%)$, and only the $10.99 \%$ works into the public sector. In the Centre-South, there is a higher share of blue-collar workers than in the North. Conversely, the share of white-collar workers is much higher in the North.

We distinguished between four classes of firm size, measured by the number of employees: small firms (1-15 employees), medium firms (16-49 and 50-250) and large firms (250 employees and over). Confirming a typical feature of the Italian economy, more than a third of the sample works in a small firm ([1-15] employees), whilst the share of large firms is slightly more than one tenth of the sample. In the Centre-South, the share of small firms is much higher than in the North and, vice versa, the share of large firms is much higher in the North.

Around $7.73 \%$ of our sample has a temporary contract. The considered share is much higher in the Centre-South than in the North. Overall, the descriptive analysis shows that the Centre-South has characteristics that are associated with a higher degree of worker turnover, which might suggest that at least part of the observed gap is explained by such characteristics.

We also include indicators for the structural change and for the degree of industrial concentration. We computed the Lilien and the Herfindahl index ${ }^{11}$ by region and year. On average, we obtain a Lilien index of 55.88\% and an Herfindahl index of $13.02 \%$ during the period 2004-2010. The average regional values for the period 2004-2010 are shown into the maps in Figures 1 and 2, respectively. The Herfindahl index is lower into the Central and Southern regions, whilst the Lilien index is instead higher into the South and highunemployment regions.

Three dummy variables for the geographical area of residence (North-West, North-East, Centre-South) are included in the model specification. In general, around one half of the sample lives in the North of Italy (almost equally distributed among North-West and NorthEast). Around 16\% of all employees live in the Centre during the period 2004-2010, whilst the remainder (around 33\%) lives in the South.

Finally, a set of time dummies for the years 2004-2010 were introduced since, as explained above, we carried out pooled estimates for the overall period.

\section{Findings}

\subsection{Descriptive analysis}

We find evidence supporting $H_{1}$ (against the alternatives of $H_{0}$ and $H_{2}$ ) in all the considered years.

The Appendix Figures A-1 through A-6 show the positive relation existing between regional unemployment rate and WT in all the years available. Figure 3 also confirms these

\footnotetext{
${ }^{11}$ The formulas of both the Herfindahl and the Lilien index are explained in Section 2.2 .
} 
Figure 1: Herfindahl Index by Region

Herfindahl index by region

Italy, pooled value 2004-'10

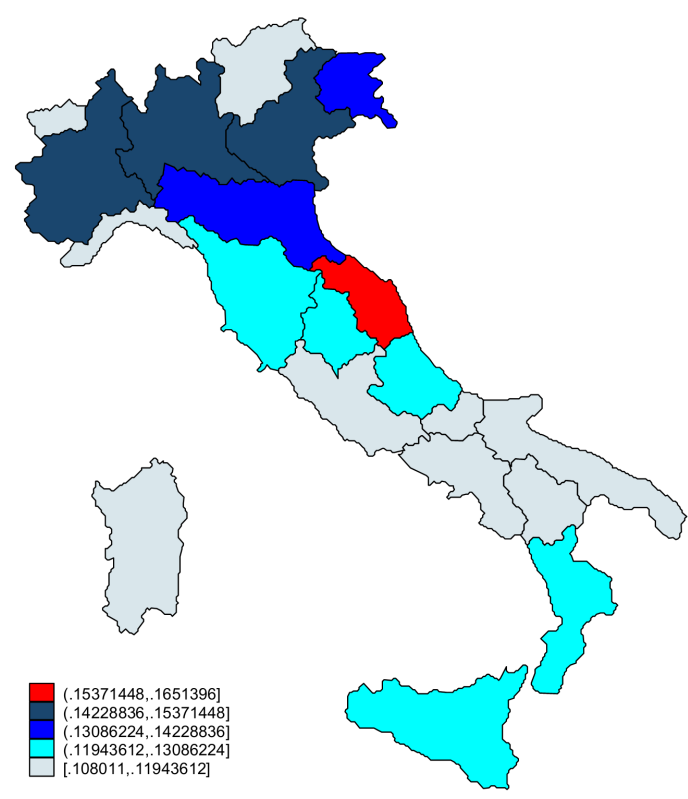

Figure 2: Lilien Index by Region

Lilien index by region

Italy, pooled value 2004-'10

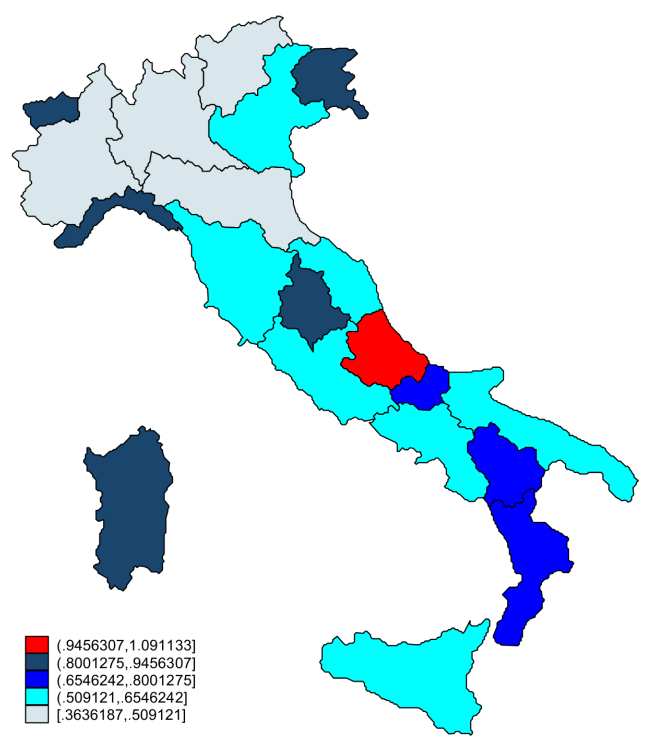


findings. The rate of worker turnover is higher in the regions where also the unemployment rate is higher.

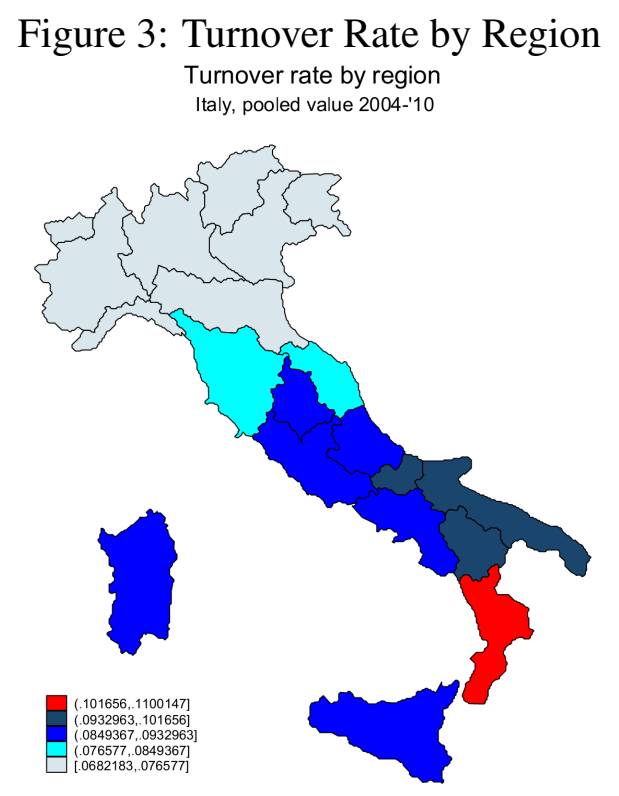

In addition, we show that there is a positive relationship between the regional rate of unemployment and the two components of worker turnover, namely the inflow to (Figure 4) and outflow from (Figure 5) unemployment, as expected considering the long-run equilibrium relationship existing among these two variables.

We indeed find the highest turnover rates in the traditionally high unemployment regions of the South of Italy. For instance, in 2004-2005 we find the highest turnover rates (22-24\%) in Campania, Puglia and Sicilia, which show the highest unemployment rates (15-17\%). This pattern is confirmed for the overall period examined. ${ }^{12}$

This is in line with the findings of Contini and Trivellato (2005) on LFS data for the decade 1993-2003 and Naticchioni et al. (2006) on ISFOL data for the period 1985-1999. Both these previous research works find a positive relation between worker turnover and regional unemployment.

We compute the worker turnover, together with its main components of inflows and outflows rates, and worker reallocation rates (two definitions explained in Section 3.1) at the NUTS1-level. Table 2 and Figures 6 through 8 display the indicators for Italy and by geographical area of residence (NUTS1 macroregions). The South is the area with the highest worker turnover and of both its components. On the other hand, the North is the

\footnotetext{
${ }^{12}$ Campania maintains the highest worker turnover rate for all the period 2004-2010, whilst Sicily maintains the highest unemployment rate. The regions of the North of Italy, instead, maintain lower turnover and unemployment rates.
} 
Figure 4: Inflow Rate by Region

Inflow rate by region

Italy, pooled value 2004-'10

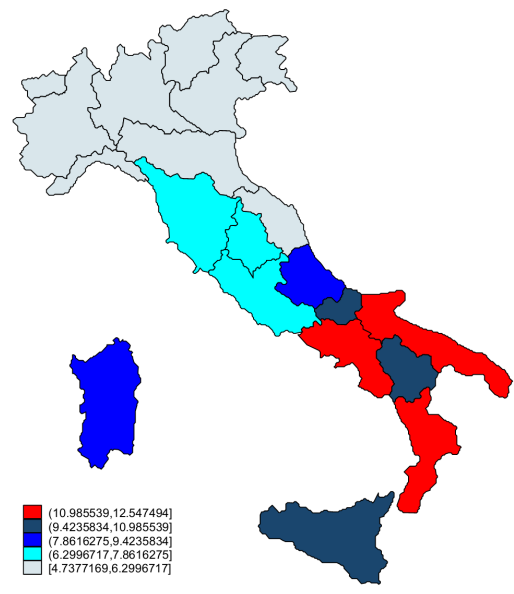

Figure 5: Outflow Rate by Region

Outflow rate by region

Italy, pooled value 2004-'10

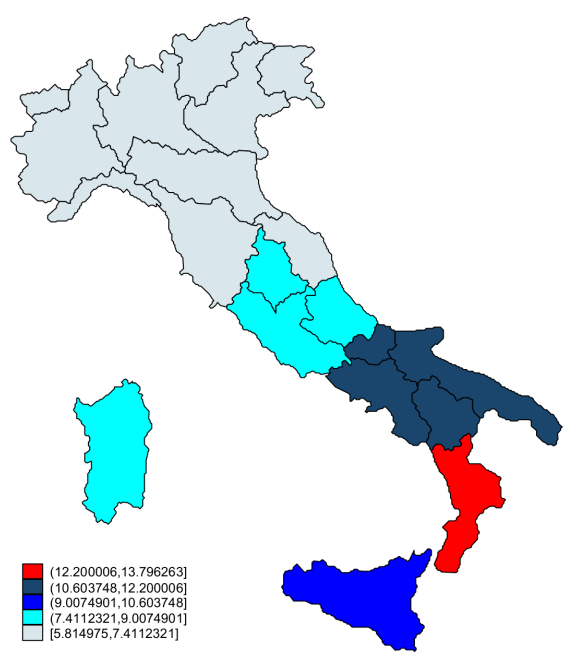


area with the lowest degree of worker mobility. For instance, in 2005-2006 the accession and separation rates of the North are half those of the South.

Table 2: Worker reallocation, worker turnover, inflow and outflow rates by area of residence, 2004-2010

\begin{tabular}{|c|c|c|c|c|c|}
\hline & Reallocation $^{\text {(a) }}$ & Reallocation $^{(\mathrm{b})}$ & Turnover & Inflow Rare & Outflow Rare \\
\hline \multicolumn{6}{|l|}{ 2004-2005 } \\
\hline North-West & 16.78 & 20.67 & 11.55 & 5.58 & 5.97 \\
\hline North-East & 16.69 & 21.96 & 11.18 & 5.20 & 5.98 \\
\hline Centre & 19.77 & 24.85 & 13.90 & 6.68 & 7.22 \\
\hline South & 26.38 & 27.41 & 21.55 & 10.64 & 10.91 \\
\hline Italy & 20.13 & 23.74 & 14.83 & 7.18 & 7.65 \\
\hline \multicolumn{6}{|l|}{ 2005-2006 } \\
\hline North-West & 15.87 & 20.37 & 10.95 & 5.42 & 5.53 \\
\hline North-East & 16.68 & 20.57 & 10.71 & 5.56 & 5.15 \\
\hline Centre & 19.26 & 21.86 & 14.51 & 8.17 & 6.34 \\
\hline South & 27.84 & 27.82 & 22.53 & 12.15 & 10.38 \\
\hline Italy & 20.15 & 25.34 & 14.93 & 7.93 & 7.00 \\
\hline \multicolumn{6}{|l|}{$2006-2007$} \\
\hline North-West & 15.81 & 25.63 & 10.60 & 5.54 & 5.06 \\
\hline North-East & 16.57 & 27.50 & 11.26 & 5.40 & 5.86 \\
\hline Centre & 19.56 & 31.03 & 13.91 & 6.13 & 7.78 \\
\hline South & 24.82 & 34.19 & 19.76 & 10.33 & 9.43 \\
\hline Italy & 19.33 & 29.62 & 14.05 & 7.01 & 7.04 \\
\hline \multicolumn{6}{|l|}{$2007-2008$} \\
\hline North-West & 17.22 & 28.05 & 11.43 & 5.62 & 5.71 \\
\hline North-East & 18.50 & 29.65 & 11.76 & 6.19 & 5.57 \\
\hline Centre & 20.60 & 30.71 & 14.26 & 7.98 & 6.28 \\
\hline South & 26.96 & 34.13 & 21.40 & 11.06 & 10.34 \\
\hline Italy & 20.96 & 30.67 & 14.89 & 7.78 & 7.11 \\
\hline \multicolumn{6}{|l|}{ 2008-2009 } \\
\hline North-West & 14.65 & 23.30 & 10.29 & 4.21 & 6.08 \\
\hline North-East & 14.81 & 22.66 & 10.88 & 4.78 & 6.10 \\
\hline Centre & 17.96 & 29.89 & 13.35 & 5.83 & 7.52 \\
\hline South & 25.94 & 30.78 & 21.27 & 10.57 & 10.70 \\
\hline Italy & 18.54 & 26.47 & 14.13 & 6.45 & 7.68 \\
\hline \multicolumn{6}{|l|}{ 2009-2010 } \\
\hline North-West & 15.80 & 21.56 & 11.91 & 5.42 & 6.49 \\
\hline North-East & 14.68 & 21.04 & 10.32 & 4.62 & 5.70 \\
\hline Centre & 25.03 & 25.56 & 13.35 & 5.76 & 7.59 \\
\hline South & 25.57 & 26.76 & 20.56 & 9.94 & 10.62 \\
\hline Italy & 18.41 & 23.72 & 14.25 & 6.57 & 7.69 \\
\hline
\end{tabular}

The WR shows the same geographical differences as the WT. It is increasing up to 2007-2008 and thereafter it is decreasing during the economic downturn. The WT, instead, exceeds $14 \%$ throughout the entire period. The recession reduces the accession rates and increases the separations from employment. Those two effects offset each other. 
Figure 6: Worker reallocation, worker turnover, Inflow and Outflow rates in Italy, 20042010

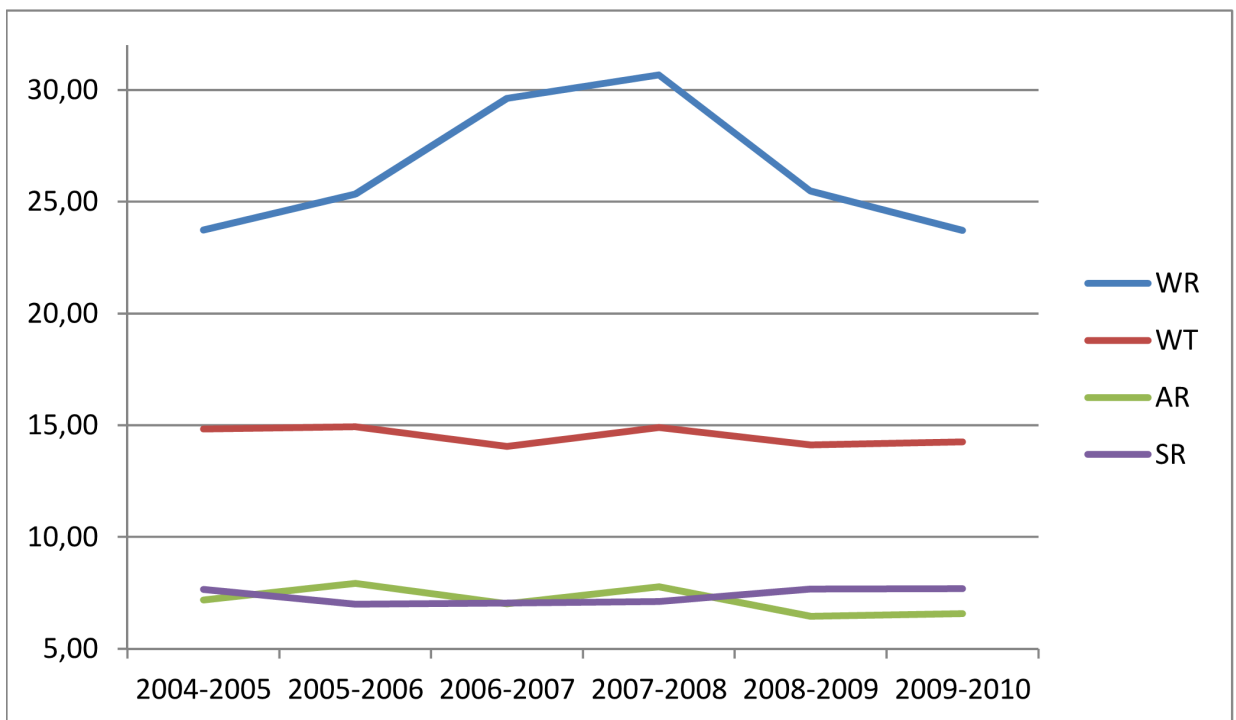

Figure 7: Worker Reallocation by Area of residence, 2004-2010

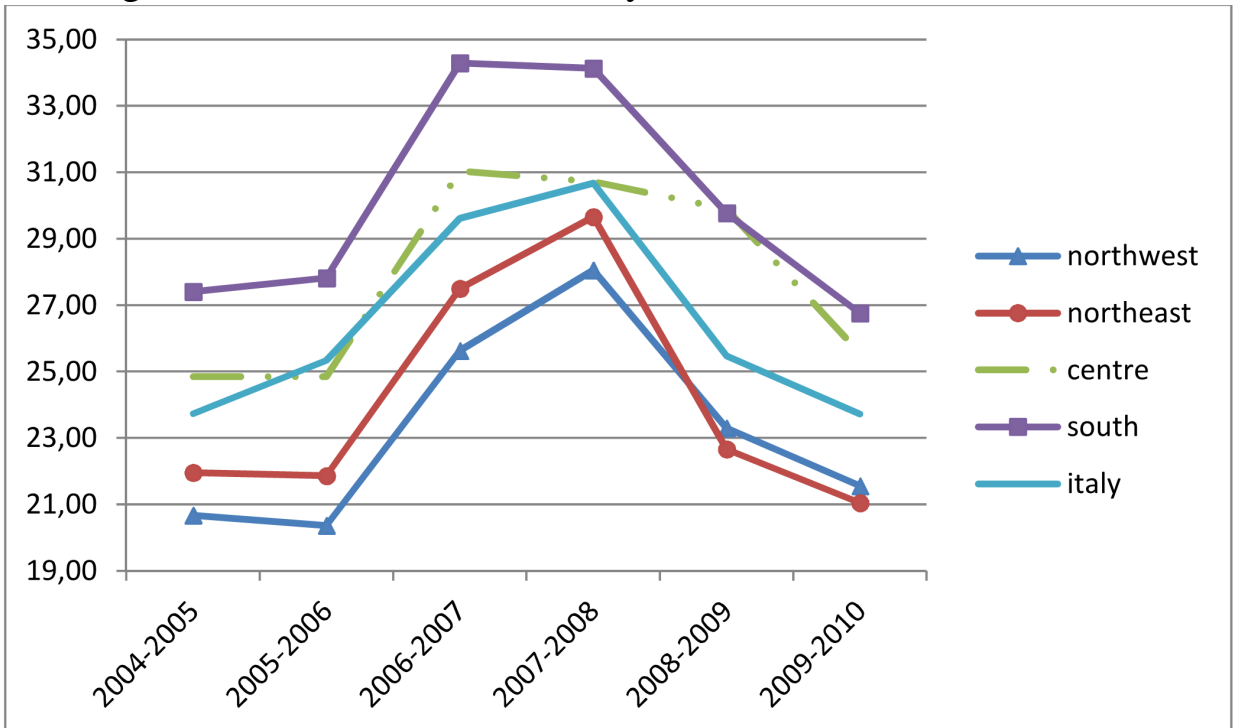


Figure 8: Worker Turnover by Area of residence, 2004-

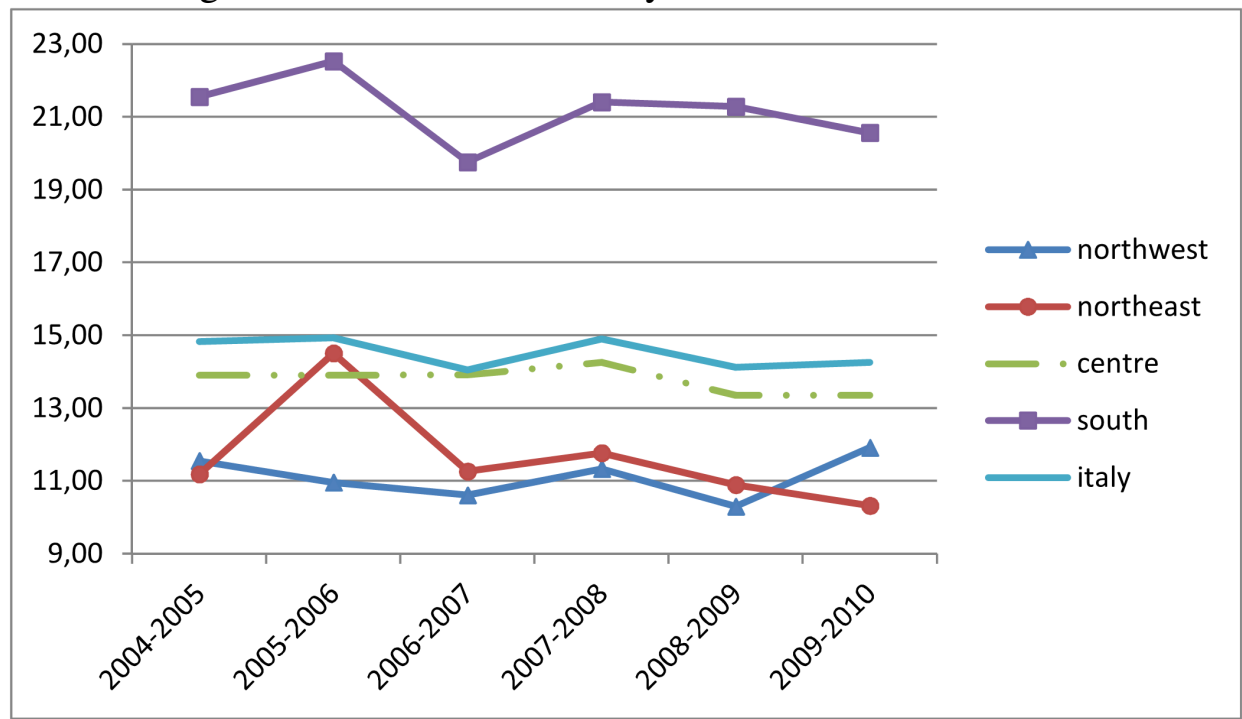

\subsection{Econometric analysis}

To understand the possible sources of worker turnover and the reasons behind the geographical differences, we estimate a simple econometric model of the probability of an individual to experience a change in her labour market status.

Our general hypothesis, discussed at length in Section 2, is that ceteris paribus a greater degree of $W T$ is related to a higher incidence of industrial turbulence in the high unemployment regions.

Table 3 reports all the estimated models. ${ }^{13}$ Model (1) only includes the areas of residence only. Model (2) introduces additional control variables, which might be candidate as determinants of worker turnover. The Models (3) and (4) introduce the Herfindahl and the Lilien index, respectively. Finally we estimate a model with all the explanatory variables (Model (5)).

Following the hypothesis explained above, it is reasonable to expect that a significant part of the WT is explained by the industrial change, controlling also for the so-called portfolio effect. Our variables of interest for this scope are indeed the Lilien and the Herfindahl index, as noted in Section 2.2.

In the first exercise, the regional dummies, taking the Centre-South as base category, appear to be significantly different (at the $1 \%$ significance level) from one another for the

\footnotetext{
${ }^{13}$ The coefficients in Table 3 detail the log odds ratio of $W T$. As the logistic model is a linear regression in the $\log$-odd ratio, $\left[\exp \left(\beta_{j}\right)-1\right] \times 100$ provides us with the impact of a unit variation of $X_{j}$ on the odd ratio. In detail, the exponential of the coefficients returns the odds ratio, which is the relative probability of the associated characteristics with respect to the baseline category.
} 
Table 3: Logit estimates on the probability of workers turnover, 2004-2010

\begin{tabular}{|c|c|c|c|c|c|}
\hline & (1) & (2) & (3) & (4) & (5) \\
\hline \multicolumn{6}{|l|}{ Macroregion-Reference: Centre-South } \\
\hline North-West & $-.581^{* * *}$ & $-.475^{* * *}$ & $-.368^{* * *}$ & $-.452^{* * *}$ & $-.356^{* * *}$ \\
\hline North-East & $-.556^{* * *}$ & $-.493^{* * *}$ & $-.415^{* * *}$ & $-.476^{* * *}$ & $-.406^{* * *}$ \\
\hline Male & & $-.596^{* * *}$ & $-.602^{* * *}$ & $-.596^{* * *}$ & $-.602^{* * *}$ \\
\hline \multicolumn{6}{|l|}{ Age-Reference: $[15,24]$} \\
\hline$[25,34]$ & & $-.577^{* * *}$ & $-.580^{* * *}$ & $-.577^{* * *}$ & $-.580^{* * *}$ \\
\hline$[35,44]$ & & $-1.027^{* * *}$ & $-1.032^{* * *}$ & $-1.027^{* * *}$ & $-1.032^{* * *}$ \\
\hline$[45,54]$ & & $-.889^{* * *}$ & $-.893^{* * *}$ & $-.889^{* * *}$ & $-.894^{* * * *}$ \\
\hline$[55,64]$ & & $.760^{* * * *}$ & $.755^{* * *}$ & $.759^{* * *}$ & $.754^{* * *}$ \\
\hline \multicolumn{6}{|c|}{ Education - Reference: Post secondary or tertiary } \\
\hline None, elementary, or lower secondary & & $.344^{* * *}$ & $.339^{* * *}$ & $.345^{* * * *}$ & $.340^{* * *}$ \\
\hline Upper secondary & & $.171^{* * *}$ & $.169^{* * *}$ & $.170^{* * * *}$ & $.169^{* * * *}$ \\
\hline \multicolumn{6}{|l|}{ Firm size-Reference: Undefined } \\
\hline$[1,15]$ & & $-4.042^{* * *}$ & $-4.038^{* * *}$ & $-4.042^{* * *}$ & $-4.038^{* * *}$ \\
\hline$[16,49]$ & & $-4.301^{* * *}$ & $-4.293^{* * *}$ & $-4.301^{* * *}$ & $-4.293^{* * *}$ \\
\hline$[50,250]$ & & $-4.432^{* * *}$ & $-4.421^{* * *}$ & $-4.431^{* * *}$ & $-4.421^{* * *}$ \\
\hline$[250$, over $]$ & & $-4.402^{* * *}$ & $-4.393^{* * *}$ & $-4.401^{* * *}$ & $-4.393^{* * *}$ \\
\hline Blue-collar & & $.770^{* * * *}$ & $.776^{* * * *}$ & $.769^{* * *}$ & $.776^{* * *}$ \\
\hline \multicolumn{6}{|l|}{ Type of contract-Reference: Permanent } \\
\hline Temporary contract & & $1.212^{* * *}$ & $1.207^{* * *}$ & $1.212^{* * * *}$ & $1.207^{* * *}$ \\
\hline \multicolumn{6}{|l|}{ Type of contract-Reference: Private } \\
\hline Public Sector & & $-.591^{* * *}$ & $-.604^{* * *}$ & $-.591^{* * *}$ & $-.604^{* * *}$ \\
\hline Herfindahl & & & $-5.003^{* * *}$ & & $-4.868^{* * *}$ \\
\hline Lilien & & & & $.112^{* * * *}$ & .074 \\
\hline Year 2005-2006 & & .056 & .047 & $.072^{*}$ & .057 \\
\hline Year 2006-2007 & & .006 & -.009 & .017 & -.002 \\
\hline Year 2007-2008 & & $.095^{* *}$ & $.079^{* *}$ & $.099^{* * *}$ & $.082^{* *}$ \\
\hline Year 2008-2009 & & $.104^{* * *}$ & $.078^{* *}$ & $.121^{* * * *}$ & $.090^{* *}$ \\
\hline Year 2009-2010 & & $.192^{* * *}$ & $.162^{* * * *}$ & $.203^{* * * *}$ & $.170^{* * *}$ \\
\hline Constant & $1.596^{* * * *}$ & $1.927^{* * *}$ & $2.550^{* * *}$ & $1.845^{* * *}$ & $2.479^{* * * *}$ \\
\hline \# of observations & & & 129,597 & & \\
\hline
\end{tabular}

Note: *significant at $10 \%$; * significant at $5 \%$; *** significant at $1 \%$.

Robust standard errors are computed using the Huber / White / sandwich estimator. The table presents the coefficients of the Logit regression. Taking the exponential of the coefficients returns the odds ratio, which latter measure the relative probability of the associated characteristics with respect to the baseline characteristics. When the odds ratio is greater than one, the associated characteristics has a higher probability of experiencing the outcome under consideration; vice versa, when the odds ratio is smaller than one, the associated characteristics has a lower probability of experiencing the outcome under consideration.

Source: Authors' elaborations on Italian Labour force survey data. 
overall period. The Centre-South is confirmed to be the area with the highest rate of worker turnover, especially if compared with the North-East of the Country. The gap between Centre-South and North-East is of about 58\%. The percentage is a bit lower (around 55\%) for the North-West.

In model (2) we add all the other possible sources of worker turnover at an individual level. As noted in Section 3.4, the Centre-South has to a greater extent than the other regions most of the characteristics that are generally associated with higher WT. We therefore expect that adding these control variables should reduce the regional gap in WT observed in unconditional estimates.

Moving from column 2 to 3 of Table 3 all the control variables play the expected role on worker turnover, but the ranking of the coefficients of regional dummies remain partially the same. The Centre-South is again the area with the highest rate of worker turnover, especially if compared to the North-East. Nonetheless, as expected, the gap between Centre-South and North-West (North-East) reduces to $47.50 \%$ (49.34\%). The role of our control variables in explaining the regional differences in worker turnover is therefore a reduction of about $18 \%$ $(11 \%)$ of the gap between Centre-South and North-West (North-East) of Italy.

Women and the youngest age segment show a higher probability of worker turnover than men and the other age groups, respectively, with the partial exception of the 55-64 age brackets. This is in line with expectations. The youngest individuals suffer typically of more career interruptions than prime-age workers. The eldest, instead, are more involved in the transitions to pre-retirement and retirement.

The probability of worker turnover reduces with increasing education and, as expected based on other studies (e.g. Naticchioni et al., 2006), with reducing firm sizes.

Finally, worker turnover increases for temporary workers. Since a large share of parttime contracts are permanent $(82.56 \%$ of part time workers in our sample have a permanent contract) it is reasonable to find a reduced turnover for such a kind of workers.

To sum up, we find evidence supporting $H_{1}$ in all the considered years. We indeed find the highest turnover rates in the traditionally high unemployment regions of the South of Italy both in unconditional estimates and conditional on several control variables catching the specific characteristics of the geographical units considered. ${ }^{14}$

In model (3) and (4), we introduce the Herfindahl and the Lilien index, respectively. We find a further reduction in the geographical differential in WT rates. In fact, industrial employment concentration and structural change in the demand for employment (Lilien index, $H_{13}$ explained above) exert a role in explaining the geographical differentials in worker turnover. Labour turnover correlates positively with structural change, as measured by the Lilien index, and negatively with the degree of industrial concentration, as measured by the

\footnotetext{
${ }^{14}$ The results are robust to alternative specifications. For instance, we estimated the same set of regressors by taking as dependent variable the WR, expressed as the number of persons whose place of employment or employment status differs between $t-1$ and $t$. The $W R$ differs significantly across regions and, as for the $W T$ it is higher into the South compared to the North of Italy. Results are not reported for the sake of brevity, but available upon request.
} 
Herfindahl index. Once we control for sectoral shifts and industrial concentration, we note a reduction of between $25 \%$ and $40 \%$ of the regional gap in terms of workers' turnover.

We now speculate on the hypothesis behind our findings for the regional distributions of the Lilien and the Herfindahl index. Our findings confirm the Lilien hypothesis above explained, according to which industrial restructuring and sectoral shifts explain the high level of WT in high unemployment regions. We indeed find a significant role of the Lilien index in our estimates for WT, and also higher values into the South of Italy. This is in line with the findings for Italy of Basile et al (2012).

The sign of the Herfindahl index is instead negative, suggesting that a higher rate of industrial concentration is a negative correlate of the degree of WT and therefore of unemployment: in other words, Marshallian effects would outweigh the portfolio effect. We find higher values of the index and, therefore, a higher degree of industrial concentration in higher employment opportunities regions of the North of Italy, compared to the CentreSouth.

Hyclak (1996) also found a negative correlation of the Herfindahl index with the local unemployment rate. Basile et al. (2012) find instead a positive association between the degree of industrial specialisation and local unemployment, suggesting that the local concentration of firms within the same industry might give rise to a lesser number of employment opportunities to dismissed workers, in addition to being more exposed to sectoral shifts.

How to explain the difference between our finding and that of Basile et al. (2012)? The most likely candidate to an explanation is the fact that we look not at local labour systems, but at larger geographical units. In the latter case, as also Marshall noted, the availability of more specialised districts could partly offset the diseconomies of specialization in terms of greater exposure to external shocks.

\section{Conclusions}

The empirical analysis of this paper builds on the theoretical model laid down in Aghion and Blanchard (1994) and the applications at a regional level suggested in Ferragina and Pastore (2008) and Caroleo and Pastore (2010).

The previous literature brings to the fore different hypotheses as to the link between local labour market dynamics - as proxied by the worker reallocation - and the unemployment rate. There are different theoretical explanations of the link between the local rate of worker turnover and of unemployment. The available empirical studies are consistent with predictions in favour of positive, negative and virtually no relationship between these variables in studies relative to different periods, countries and type of data.

In this paper, an attempt was made to quantitatively verify the empirical pattern linking labour turnover and the unemployment rate using a rich individual level dataset, namely the longitudinal files of the Italian labour force survey encompassing the period 2004-2010. 
Pooled estimates of the probability of experiencing a worker reallocation suggest a statistically significant and economically large difference across regions at both a NUTS1 and NUTS2 level. In addition, such a geographical gap positively correlates with that in unemployment rates. The rate of worker turnover is highest into the high unemployment CentreSouth of Italy.

When we look at the determinants of the regional gap in turnover rates, we find that women, the youngest age segment as well as the least educated employees experience the highest probability of worker turnover. This latter is also associated to temporary work contracts and small firm size. Due to the greater concentration of young workers in small and medium sized enterprises, often holding a temporary contract, in high unemployment regions, we find that the gap between the Centre-South and the North-West reduces by $18 \%$ and that with the North-East reduces by $11 \%$.

More importantly, from the point of view of our theoretical hypotheses, we find that worker turnover across NUTS1 and NUTS2 units correlates positively with structural change, as measured by the Lilien index, and negatively with the degree of industrial concentration, as measured by the Herfindahl index. Once we control for sectoral shifts and industrial concentration, we note a reduction of between 25 and $40 \%$ of the regional gap in terms of workers' turnover.

Future research will attempt to disentangle different components of the variability in employment shares (Lilien index), and in particular the component due to structural change and the component due to alterations of the institutional framework. A special focus will be on assessing the impact on structural change of changes in the shares of temporary workers as distinct from changes in the shares of permanent workers. 


\section{Appendix}

\section{A-1 Figures}

Figure A-1: Regional unemployment and worker turnover, 2004-2005

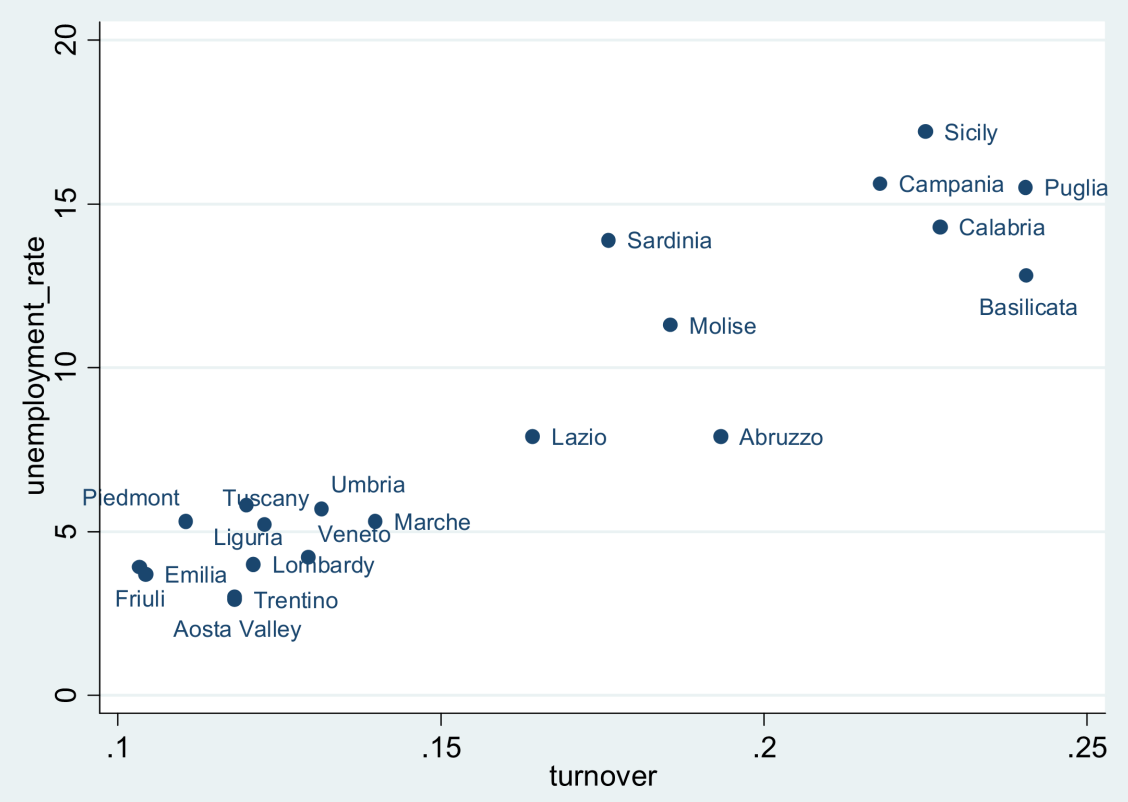


Figure A-2: Regional unemployment and worker turnover, 2005-2006

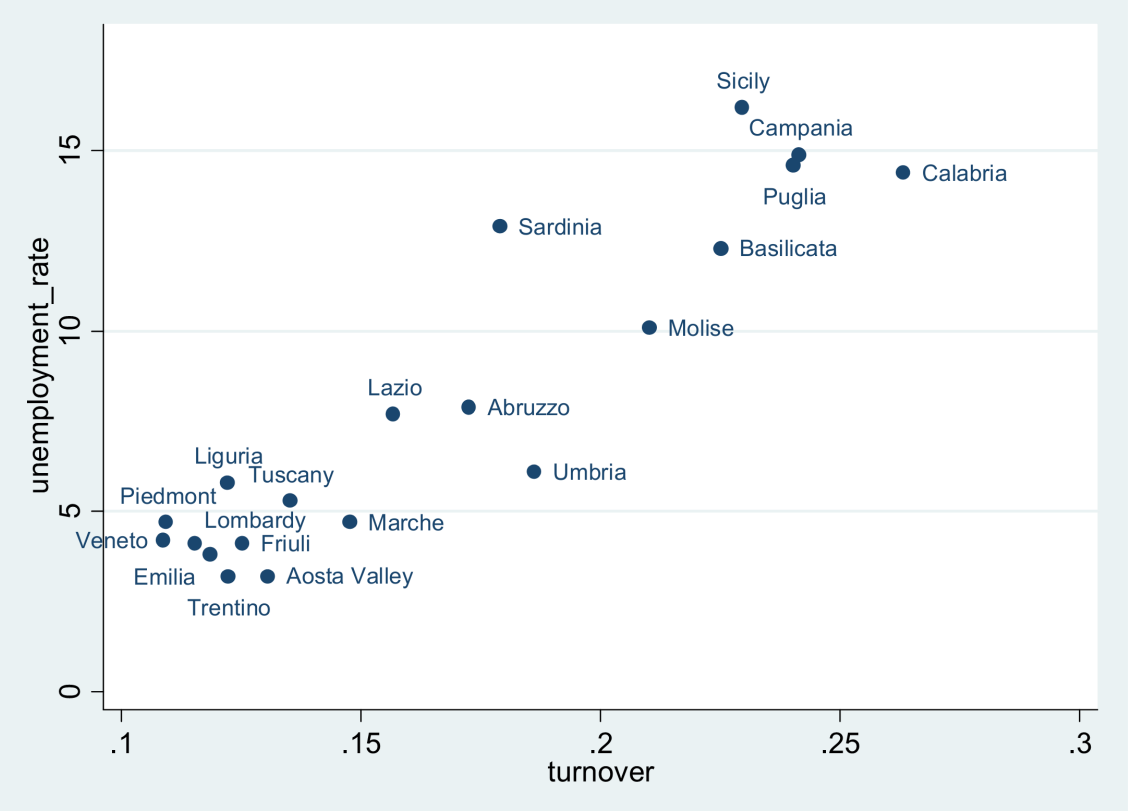

Figure A-3: Regional unemployment and worker turnover, 2006-2007

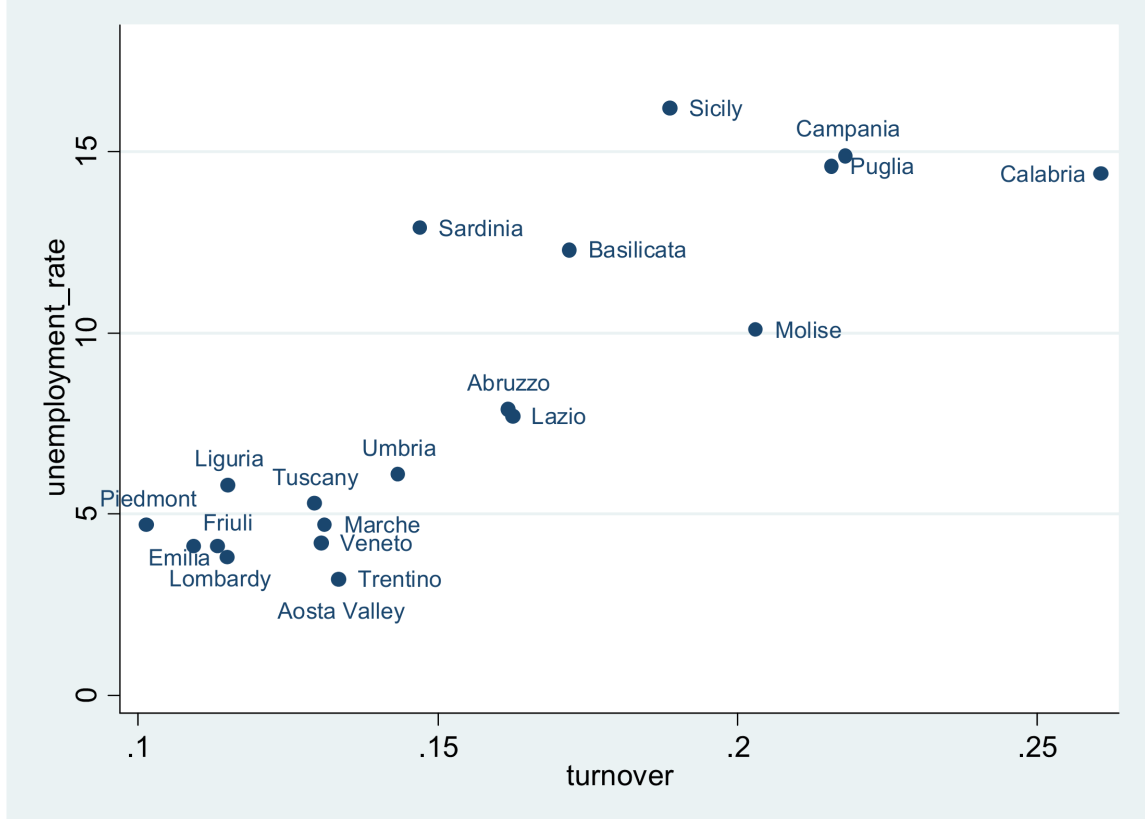


Figure A-4: Regional unemployment and worker turnover, 2007-2008

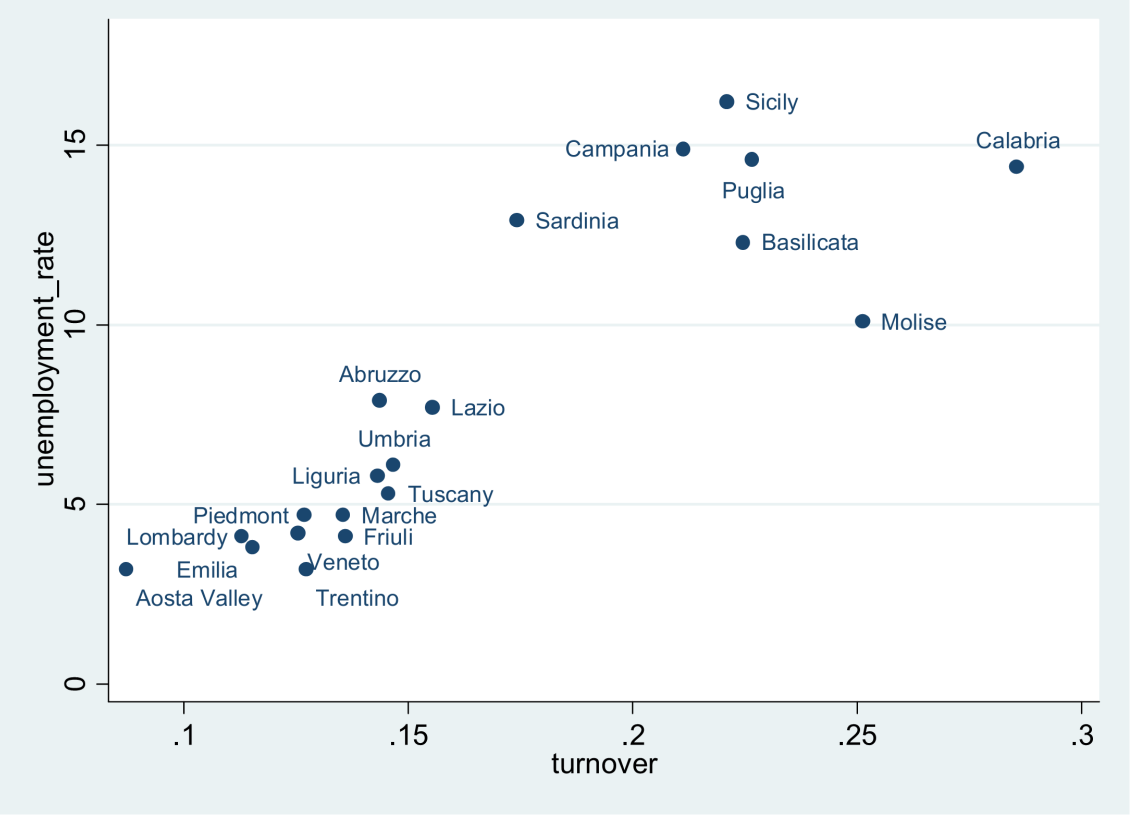

Figure A-5: Regional unemployment and worker turnover, 2008-2009

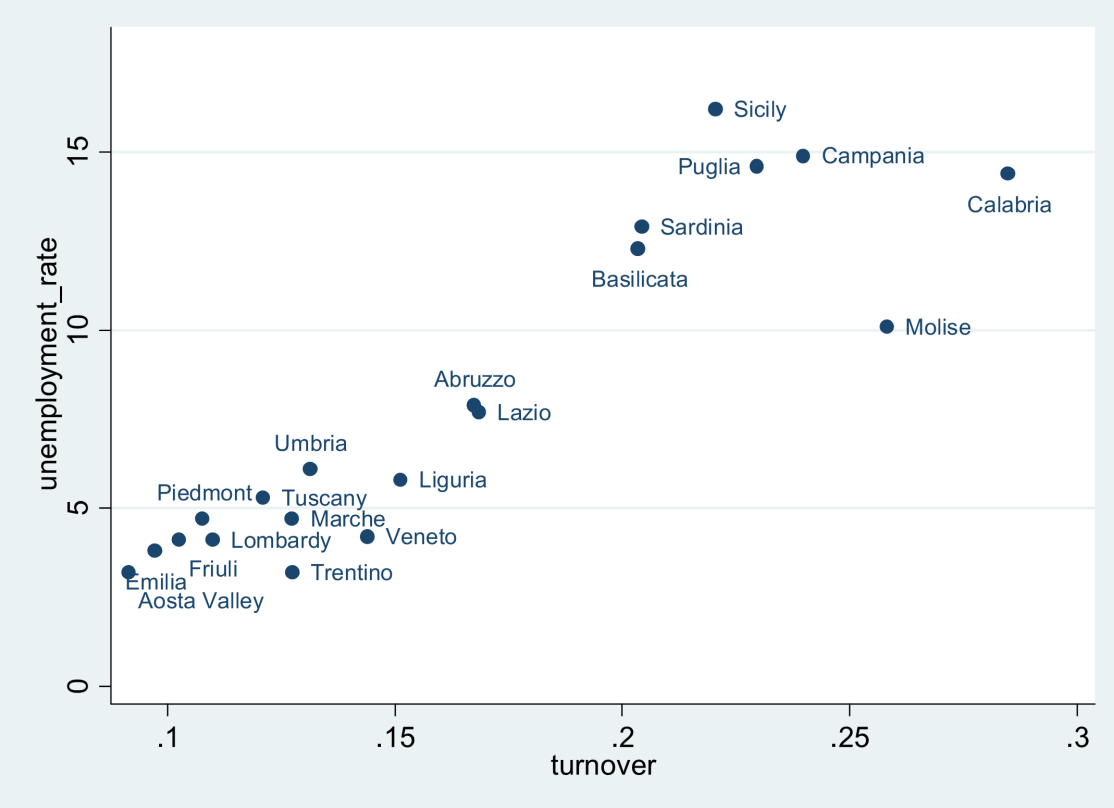


Figure A-6: Regional unemployment and worker turnover, 2009-2010

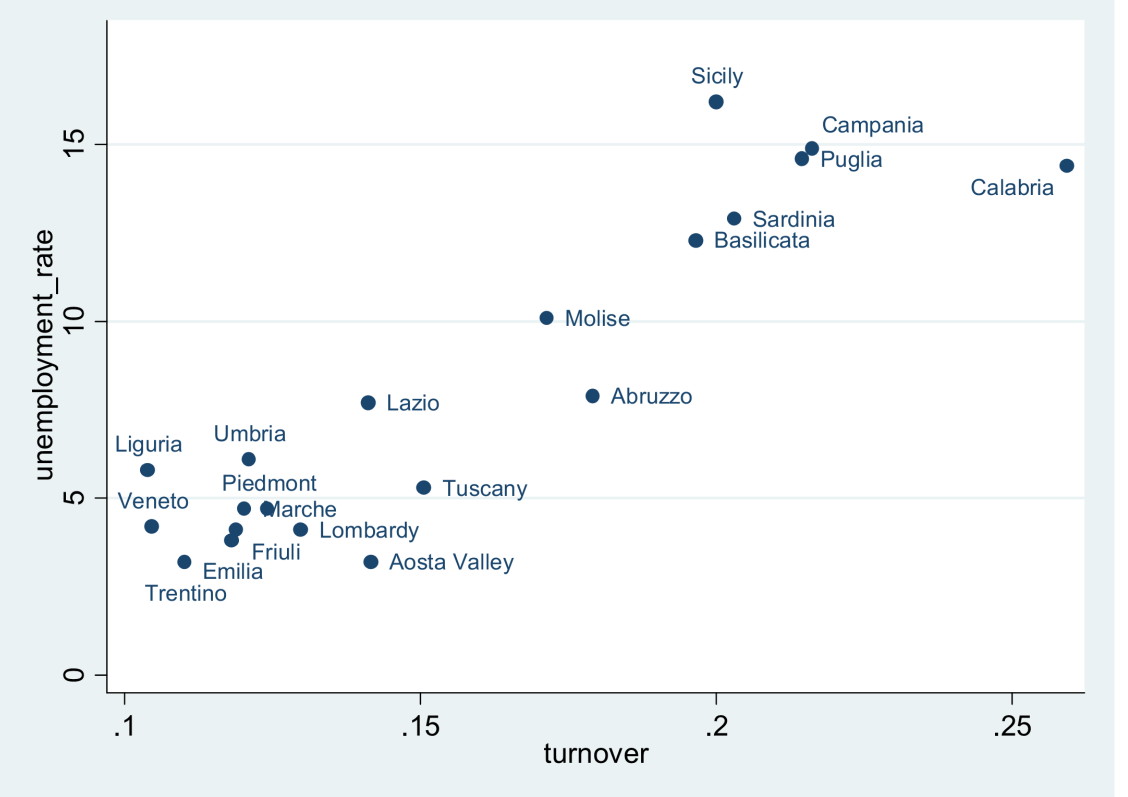




\section{References}

Abraham, K. G and L. F. Katz, "Cyclical Unemployment: Sectoral Shifts or Aggregate Disturbances?," Journal of Political Economy, 1996, 94 (3), 507-522.

Aghion, P. and O. Blanchard, "On the Speed of Transition in Central Europe," NBER Macroeconomics Annual, 1994, pp. 283-320.

Armstrong, H. and J. Taylor, "Spatial Variations in the Male Unemployment Inflow Rate," Applied Economics, 1985, 17 (1), 41-54.

Bachman, R. and D. Peggy, "The Importance of Two-Sided Heterogeneity for the Cyclicality of Labour Market Dynamics,” 2009. SFB 649 Discussion Papers, Humboldt Universität, Berlin, Germany.

Barbone, L., D.J. Marchetti, and S. Paternostro, "The Early Stages of Reform in Polish Manufacturing. Structural adjustment, Ownership and Size," The Economics of Transition, 1999, 7, 157-177.

Basile, R., A. Girardi, M. Mantuano, and F. Pastore, "Sectoral Shifts, Diversification and Regional Unemployment: Evidence from Local Labour Systems in Italy," Empirica, 2012, 39.

Berg, A., "Does Macroeconomic Reform Cause Structural Adjustment? Lessons from Poland," Journal of Comparative Economics, 1994, 18 (3), 376-409.

Blanchard, O.J. and L. Summers, "Hysteresis and the European Unemployment Problem," 1986. NBER Macroeconomics Annual, Ch. 1.

— and P. Diamond, "The cyclical behaviour of gross flows of US workers," Brookings Papers on Economics Activity, 1990, 2, 85-143.

Bockerman, P., "Unraveling the Mystery of Regional Unemployment in Finland," Regional Studies, 2003, 37 (4), 331-340.

Boeri, T., “Is Job Turnover Countercyclical?,” Journal of Labour Economics, 1996, 14 (4), 603-625.

_ , Structural Change, Welfare Systems, and Labour Reallocation, Oxford: Oxford University Press, 2000.

- and S. Scarpetta, "Regional Mismatch and the Transition to a Market Economy," Labour Economics, 1996, 3 (3), 233-254.

Broersma, L., "). Competition between Employed and Unemployed Job Searchers: is there a Difference between the UK and the Netherlands?," Applied Economic Letters, 1997, 4 (3), 199-203.

Burda, M. and C. Wyplosz, "Gross Worker and Job Flows in Europe," European Economic Review, 1994, 38 (6), 1287-1315.

Burgess, S.M., "A Model of Competition between Unemployed and Employed Job Searchers: An Application to the Unemployment Outflow Rate in Britain," The Economic Journal, 1993, 103, 1190-1204.

_ and S. Profit, "Externalities in the Matching of Workers and Firms in Britain," Labour Economics, 1993, 8 (3), 313-333. 
Caroleo, F. E and F. Pastore, "Structural Change and Labour Reallocation across Regions. A Review of the Literature," in Heidelberg Physica Verlag, ed., The Labour Market Impact of the EU Enlargement. A New Regional Geography of Europe?, 2010, pp. 17-48.

Chiarini, B. and P. Piselli, "Unemployment, Wage Pressure and Sectoral Shifts: Permanent and Temporary Consequences of Intersectoral Shifts," Journal of Policy Modelling, 2000, 22 (22), 777-799.

Contini, B., Labour Mobility and wage dynamics, Torino: Rosemberg and Sellier publishing, 2002.

_ and U. Trivellato, Eppur si muove. Dinamiche e persistenze nel mercato del lavoro italiano, Bologna: Il Mulino, 2005.

Davis, S. and J. Haltiwanger, "Gross Job Creation, Gross Job Destruction, and Employment Reallocation," The Quarterly Journal of Economics, 1992, 107 (3), 819-863.

_ and _ , "Measuring Worker and Job Flows," 1995. NBER, Working Paper No. 5133.

_ , _ , and F. Schuh, Job creation and destruction, Cambridge (MA): MIT Press, 1996.

Discenza, A. and C. Lucarelli, "Dati longitudinali a 12 mesi di distanza - Aspetti metodologici," 2009. ISTAT.

Elhorst, J.P., "The Mystery of Regional Unemployment Differentials. Theoretical and Empirical Explanations," Journal of Economic Surveys, 2003, 17 (5), 709-748.

Elsby, M., R. Michaels, and G. Solon, "The Ins and Outs of Cyclical Unemployment," American Economic Journal: Macroeconomics, 2009, l (1), 84-110.

Eriksson, M. and J. Lagerström, "Competition between Employed and Unemployed Job Applicants: Swedish Evidence,” Scandinavian Journal of Economics, 2006, 108 (3), 373-396.

Ferragina, A. M. and F. Pastore, "Mind the Gap: Unemployment in the New EU Regions," Journal of Economic Surveys, 2008, 22 (1), 73-113.

Fortin, M. and A. Araar, "Sectoral Shifts, Stock Market Dispersion and Unemployment in Canada," Applied Economics, 19977, 29 (6), 829-839.

Fujita, S. and G. Ramey, "The Cyclicality of Separation and Job Finding Rates," International Economic Review, 2009, 50 (2), 415-430.

Funck, B. and L. Pizzati, "Labour, Employment and Social Policy in the EU Enlargement Process. Changing Perspectives and Policy Options," 2002. Washington, D.C.: World Bank.

_ and _ , "European Integration, Regional Policy and Growth,” 2003. Washington, D.C.: World Bank.

Garonna, P. and F. Sica, "Intersectoral Labour Reallocations and Unemployment in Italy," Labour Economics, 2000, 7 (6), 711-728.

Gazzelloni, S., "La rilevazione sulle forze di lavoro: contenuti, metodologie, organizzazione,” 2006. ISTAT Metodi e Norme n. 32, 2006, Roma.

Glaeser, E., H. Kallal, J. Scheinkman, and Shleifer A., "Growth in Cities," Journal of Political Economy, 1992, 100 (6), 1126-1152. 
Hall, R., "Employment Efficiency and Sticky Wages: Evidence form Flows in the Labor Market," Review of Economics and Statistics, 2005, 87 (3), 397-407.

Holzer, H.J., "Employment, Unemployment and Demand Shifts in Local Labour Markets," Review of Economics and Statistics, 1991, 73 (1), 25-32.

Hyclak, T., "Structural Changes in Labour Demand and Unemployment in Local Labour Markets," Journal of Regional Science, 1996, 36 (4), 653-663.

ISTAT, "Nota metodologica allegata alla diffusione dei file MFR, Dicembre 2009,” 2009.

Jacobs, J., “The Economy of Cities,” 1969. Random House, New York.

Krajnyàk, K. and M. Sommer, “Czech Republic,” 2004. IMF country Report, n. 4/265, August.

Krugman, P., "Past and Prospective Causes of High Unemployment," Economic Review, 1994, pp. $23-43$.

Layard, R., S. Nickell, and R Jackman, Unemployment. Macroeconomic performance and the labour market, Oxford: Oxford University Press, 1991.

Marshall, A., Principles of Economics, London: MacMillan, 1890.

Naticchioni, P., E. Rustichelli, and A. Scialà, "Employment Protection and Regional Labour Market Flows," Economia Politica, 2006, 23 (3), 453-474.

Neelin, J., "Sectoral Shifts and Canadian Unemployment," Review of Economics and Statistics, 1987, 69 (4), $718-723$.

Neumann, G. R. and R.H. Topel, "Employment Risk, Diversification, and Unemployment," Quarterly Journal of Economics, 1973, 106 (4), 1341-1365.

Newell, A. and F. Pastore, "Regional Unemployment and Industrial Restructuring in Poland," Eastern European Economics, 2006, 44 (3), 5-28.

OECD, The OECD Jobs Study 1994. Paris, OECD.

Pastore, F. and J. Tyrowicz, "Labour Turnover and the Spatial Distribution of Unemployment. A Panel Data Analysis using Employment Registry Data," 2010. XXV AIEL Conference, University of Chieti and Pescara.

Petrongolo, B. and C. Pissarides, "The Ins and the Outs of European Unemployment," American Economic Review, 2008, 98 (2), 256-262.

Robson, M., "Regional Variations in the Competitiveness of Unemployed Job-Seekers and the Rate of Outflows from Unemployment," Oxford Bulletin of Economics and Statistics, 2001, 63 (1), 61-90.

_ , "Structural Change, Specialization and Regional Labour Market Performance: Evidence for the UK," Applied Economics, 2009, 41 (3), 275-293.

Rutkowski, J., "Rapid Labour Reallocation with a Stagnant Unemployment Pool: The Puzzle of the Labour Market in Lithuania,” 2003. World Bank, Policy Research working paper series, n. 2946.

Shimer, R., "Reassessing the Ins and Outs of Unemployment," 2007. NBER Working Papers, N 13421. 
Simon, C. J., "Frictional Unemployment and the Role of Industrial Diversity," Quarterly Journal of Economics, 1988, 103 (4), 715-728.

_ and C. Nardinelli, "Does Unemployment Diversity always Reduce unemployment? Evidence from the Great Depression and After," Economic Enquiry, 1992, 30 (2), 384-397.

Van Ours, J.C., “An Empirical Note on Employed and Unemployed Job Search,” Economics Letters, 1995, 49 (4), 447-452.

WorldBank, "Poland-Labor Market Study: The Challenge of Job Creation," 2001. World Bank Country Study, March. 